\title{
Esfera Pública Transnacional e Meio Ambiente: 0 caso Avaaz versus Bayer
}

\author{
Sabrina Leme ${ }^{1}$
}

\section{RESUMO}

Analisando o "pano de fundo" das negociações da Comissão Europeia sobre a proibição de três tipos de pesticidas neonicotinóides, verificou-se a existência de uma enérgica esfera pública transnacional que trouxe à tona o debate científico sobre os efeitos desses pesticidas sobre diversas espécies de abelhas. Com argumentos científicos e petições com milhões de assinaturas, foi travada uma batalha entre a rede Avaaz e a poderosa empresa Bayer.

Palavras-chave: Esfera Pública Transnacional; Riscos Ambientais; Comissão Europeia.

As abelhas sobreviverão na Europa. Se fôssemos resumir, em uma frase, as últimas negociações europeias sobre meio ambiente, essa seria: as abelhas sobreviverão na Europa. Pelo menos por enquanto.

Em 16 de janeiro de 2013, a Agência Europeia de Segurança Alimentar (EFSA) anunciou que três tipos de inseticidas neonicotinóides produzidos pelas empresas Syngenta e Bayer e usados nas lavouras de milho, canola, girassol e algodão afetavam a saúde das abelhas ${ }^{2}$. Ficou comprovada a relação destes inseticidas com a ocorrência do Distúrbio do Colapso das Colmeias - Colony Collapse Disorder (CCD) - cujo prejuízo se dá ao sistema nervoso das abelhas, afetando, sobretudo, o olfato e a memória das mesmas, elementos essenciais para manutenção das colmeias.

\footnotetext{
${ }^{1}$ Mestranda pelo Programa de Pós-Graduação em Ciência Política da Universidade Federal do Paraná, na linha de pesquisa de Organizações Internacionais. Bacharel em Relações Internacionais pela Pontifícia Universidade Católica de São Paulo. Pesquisadora do Núcleo de Pesquisas em Relações Internacionais da Universidade Federal do Paraná (NEPRI-UFPR).

${ }^{2}$ EFSA Report disponível em: http://ec.europa.eu/food/animal/liveanimals/bees/neonicotinoids en.htm. Último acesso 22.05.2013.
} 
Com base no estudo, a Comissão Europeia iniciou negociações para a proibição do uso dos compostos pelos próximos dois anos no continente. A comunidade Avaaz teve papel fundamental no processo decisório da Comissão Europeia. A Avaaz - que significa "voz" em várias línguas europeias, do oriente médio e asiáticas - é uma rede transnacional que opera apenas por meio digital, utilizando como forma de luta abaixoassinados, aos quais aderimos facilmente. Surgiu em 2007, e, atualmente, possui versão em 15 línguas e equipes em quatro continentes, descrevendo-se como "uma comunidade de mobilização online que leva a voz da sociedade civil para a política global”3.

Em posse de uma petição com mais de 2,5 milhões de assinaturas, a Avaaz pressionou os representantes dos países pertencentes à União Europeia a votarem a proibição dos três tipos de pesticidas. Do outro lado as empresas produtoras, em especial a alemã Bayer, resistiam para que os pesticidas neonicotinóides mantivessemse no mercado. "Uma queda de braço" que durou, aproximadamente, dois anos e teve início com o movimento de apicultores e ambientalistas franceses pressionando o Ministro da Agricultura da França, com o apoio da Avaaz, a partir de uma petição que recolheu um milhão de assinatura. 0 debate seguiu com nova petição "BAYER: Save the Bees!”, direcionada aos sócios majoritários da Bayer, com mais de um milhão de assinaturas, solicitando o fim do comércio dos pesticidas baseados em clothianidin, imidacloprid e thiametoxam. No dia 30 de abril de 2012, a Avaaz anunciou a derrota na reivindicação - uma vez que a reunião da Bayer decidiu por continuar produzindo os pesticidas a base de neonicotinóides - ao mesmo tempo que anunciou: (i) uma nova mobilização de assinaturas levaria a petição ao Conselho Administrativo e ao Conselho de Supervisão da Bayer4; (ii) que o próximo passo seria levar a reivindicação para regulação governamental ${ }^{5}$.

Destinada aos policy makers da União Europeia, uma nova petição foi mobilizada após o relatório da EFSA. No dia 29 de janeiro de 2013, a Avaaz anunciou que, silenciosamente, bilhões de abelhas estão morrendo em todo o mundo e que se a

\footnotetext{
${ }^{3}$ Informações do próprio site Avaaz, disponível em: http://www.avaaz.org/po/about.php. Último acesso em 03.06.2013.

4 Tradução minha para Board of Management e Supervisory Board of Bayer.

${ }^{5}$ Petição disponível em: http://www.avaaz.org/en/bayer_save the bees db/. Último acesso 22.05.2013.
} 
União Europeia tomasse medidas cabíveis contra os agrotóxicos neonicotinóides, pavimentaria o caminho para uma proibição em escala global. No dia $1^{\circ}$ de fevereiro de 2013, a Avaaz já divulgava que a Comissão Europeia havia recomendado a suspensão dos três pesticidas: era a primeira vitória antes da decisão final. 0 texto da petição ainda relatava que a empresa Bayer e outras grandes produtoras estavam fazendo lobby para manter os pesticidas no mercado. ${ }^{6}$

Quatro países europeus já haviam anunciado a proibição. No entanto, os riscos ambientais não conhecem fronteiras. No caso europeu, o modelo político de integração auxilia a construção de medidas mitigatórias conjuntas ou unificadas, permitindo que o meio ambiente seja percebido de forma também integrada. Só o modelo de integração do continente, entretanto, não consegue deter os efeitos da modernização que implica tecnologias ameaçadoras. Ulrich Beck já avistava na década de 1980 - após o evento de Chernobyl - que vivemos em uma sociedade de ameaças, baseada na produção e distribuição de riscos versus a distribuição de riquezas (BECK, 2010). Segundo Beck, na sociedade atual é preciso que haja uma esfera pública capaz de avançar com a promessa de segurança (BECK, 2010). Nas palavras de Beck,

\begin{abstract}
"Às questões do desenvolvimento e do emprego de tecnologias (no âmbito da natureza, da sociedade e da personalidade) sobrepõem-se questões do "manejo" político e científico - administração, descoberta, integração, prevenção, acobertamento - dos riscos de tecnologias efetiva ou potencialmente empregáveis, tendo em vista horizontes de relevância a serem especificamente definidos. A promessa de segurança avança com os riscos e precisa ser, diante de uma esfera pública alerta e crítica, continuamente reforçada por meio de intervenções cosméticas ou efetivas no desenvolvimento técnico-econômico." (BECK, 2010, p. 24)
\end{abstract}

O estado de arte do debate científico é importante para entender as negociações sobre o tema. Entretanto, é ainda mais relevante destacarmos o estado de arte da esfera pública transnacional que se formou em torno da questão do uso dos pesticidas neonicotinóides. Para entendermos tal esfera, partir-se-á da notícia que "correu o

\footnotetext{
${ }^{6}$ Petição disponível em: http://www.avaaz.org/po/hours to save the bees/. Último acesso 22.05.2013.
} 
mundo" através da própria Avaaz no dia 1ํ de maio de 2013, que veio com a seguinte chamada:

\begin{abstract}
"Conseguimos -- a Europa acabou de votar uma proibição aos pesticidas de abelhas! Grandes empresas como a Bayer lutaram com toda força contra a proposta, mas o poder popular, a ciência e a boa governança foi (sic) mais forte!!" (AVAAZ, 1/05/2013)
\end{abstract}

A chamada apresenta os fundamentos dessa esfera pública transnacional: de mobilização popular, sobretudo, virtual, de valorização da democracia, baseada na ciência, e creditada na governança global, ou seja, de grande pressão junto a governantes.

O conceito de esfera pública foi trazido às Ciências Sociais por Jürgen Habermas e foi reformulado pelo autor em novas obras, sendo o sentido mais contemporâneo o debatido em Mudança Estrutural da Esfera Pública (HABERMAS, 2008). Inicialmente Habermas pensou a esfera pública no contexto europeu do século XVIII com o advento da sociedade burguesa - uma sociedade que lê, tem interesses claros e convive com o aparecimento de meios de divulgação como a imprensa, ou seja, uma sociedade em condições adequadas e propensas para o surgimento de uma esfera na qual os indivíduos podem debater informações e emitir opiniões e pressionar o Estado. Assim, a esfera pública habermaseana pode ser entendida como o espaço de informação e opinião entre a sociedade civil e o Estado (CASTELLS, 2008, p. 78).

Nas obras mais recentes, em especial a mencionada, Habermas adequou o conceito de esfera pública ao contexto dos debates sociais atuais. Em uma releitura pertinente, Manuel Castells (2008) apresenta o surgimento de uma nova esfera pública, baseada numa sociedade civil globalizada, integrada por redes de comunicação e fundada na governança global. Espaços físicos, sobretudo em cidades e universidades, sempre tiveram papel importante na esfera pública, bem como a mídia foi fundamental para a esfera pública na sociedade industrial. Porém, em uma sociedade em rede como a atual, nada mais óbvio que a organização da esfera pública se dê em redes de

\footnotetext{
${ }^{7}$ Comunicado eletrônico (email) aos membros da rede, enviado por Ricken Patel, em 1ํo de maio de 2013.
} 
comunicação (CASTELLS, 2008). 0 caráter transnacional surge com a globalização e com o entendimento de que os novos temas sociais dizem respeito a cidadãos globais. No caso em tela, a relação da esfera pública com Estados-nacionais existe, como foi possível verificar em uma das petições, mobilizada pela Avaaz, que recolheu 150 mil assinaturas, e que foi entregue ao governo alemão com o objetivo de mudar o voto deste na Comissão Europeia - objetivo que foi alcançado.

Em 15 de março de 2013, a Comissão Europeia não havia alcançado a maioria qualificada na votação: foram treze votos a favor da proibição, nove votos contrários e cinco abstenções. Apenas em 29 de abril de 2013 a decisão foi tomada: dos vinte e sete Estados-membros, quinze votaram a favor da proposta de restrição ao uso dos pesticidas, oito Estados-membros votaram contra e quatro se abstiveram. ${ }^{8}$ Dentre os Estados que votaram contra a proposta de proibição estão Portugal e Grã-Bretanha.

O jornal britânico The Independent, em 28 de abril de 2013, relatou que a GrãBretanha votou contra por causa de uma eventual falta de evidência científica para a adoção da medida proibitória. Ora, tal argumento é infundado, uma vez que o Princípio da Precaução é princípio fundamental do direito ambiental e propõe que, no caso em que haja indícios de sérios riscos ambientais, as autoridades não deveriam alegar falta de evidência científica para deixar de tomar as providências cabíveis (LISBOA, 2002).

As restrições serão aplicadas a partir de 1ํ de dezembro de 2013. Agora resta saber quais serão os próximos passos dessa esfera pública em direção aos outros "cantos" do planeta.

\section{Referências Bibliográficas}

BECK, Ulrich, 2010. Sociedade de risco: rumo a uma outra modernidade. São Paulo, Ed. 34.

CASTELLS, Manuel. The New Puclic Sphere: Global Civil Society, Communication Networks, and Global Governance. The ANNALS of the American Academy, AAPSS, 616, Março 2008.

\footnotetext{
${ }^{8}$ Disponível em http://ec.europa.eu/ireland/press office/news of the day/proposal-to-restrict-use-ofneonicotinoid-insecticidest en.htm. Último acesso 22.05.2013.
} 
COHEN, Jean L.. Sociedade Civil e Globalização: Repensando Categorias. DADOS - Revista de Ciências Sociais, Rio de Janeiro, Vol. 46, nº 3, 2003, pp. 419-459.

HABERMAS, Jünger, Mudança Estrutural de Esfera Pública: investigações quanto a uma categoria da sociedade burguesa. Rio de Janeiro: Tempo Brasileiro, 2008.

LISBOA, Marijane, 2002. Em busca de uma política externa brasileira de meio ambiente: três exemplos e uma exceção à regra. In São Paulo em Perspectiva, Vol. 16, no. 2, abril/junho, São Paulo. 